\title{
Editorial: Political Psychology: The Role of Personality in Politics
}

\author{
Julie Blais ${ }^{1 * t}$, Philip G. Chen ${ }^{2 \dagger}$ and Scott Pruysers ${ }^{3 \dagger}$ \\ ${ }^{1}$ Department of Psychology and Neuroscience, Dalhousie University, Halifax, NS, Canada, ${ }^{2}$ Department Political Science, Beloit \\ College, Beloit, WI, United States, ${ }^{3}$ Department of Political Science, Dalhousie University, Halifax, NS, Canada
}

Keywords: politics, personality, political behavior, dark triad, big five

Editorial on the Research Topic

Political Psychology: The Role of Personality in Politics

\section{INTRODUCTION}

\section{What is Personality?}

Why do electors develop preferences for certain political parties and their leaders? Why do some individuals engage in political activism more frequently than others? How can we explain divergent policy preferences among citizens? These, and similar questions, have been studied by political scientists for decades. While much of the literature has focused on factors such as sociodemographic characteristics, partisanship, and ideology (Campbell et al., 1960; Converse, 1972; Marsh and Kaase, 1979), at last part of our understanding of political behavior must be rooted in individual differences in personality. As Feist and Feist (2009) note, "although no single definition is acceptable to all personality theorists, we can say that personality is a pattern of relatively permanent traits and unique characteristics that give both consistency and individuality to a person's behavior" (p. 4).

Perhaps, the most common way of studying personality has been through the trait approach. Traits, or dispositions, refer to the characteristics that are internal to the person, that are reasonably stable over time and across situations, and that help to explain differences between individuals (Larsen et al., 2018). There are now several different models that help organize various personality traits, with the Five Factor Model (FFM; McCrae and Costa, 1987) being the most prominent. The FFM includes the traits of extraversion (e.g., gregariousness, assertiveness, and excitement-seeking), agreeableness (e.g., trust, modesty, warmth), conscientiousness (e.g., competence, self-discipline, and achievement-striving), neuroticism (e.g., anxiety, irritability, and vulnerability), and openness to experience (e.g., ideas, fantasy, and unconventional values). A competing model, the HEXACO (Ashton and Lee, 2007), similarly includes the traits of extraversion, conscientiousness, and openness; however, the HEXACO re-defines agreeableness (e.g., forgiveness, gentleness, and patience) and neuroticism (changing the name to emotional stability) while also adding the sixth trait of honesty-humility (e.g., fairness, greed avoidance, modesty). In contrast to these general traits, the Dark Triad (Paulhus and Williams, 2002) defines the three more malevolent traits of psychopathy (e.g., callousness, impulsivity, antagonism), narcissism (e.g., selfaggrandizement, antagonism), and Machiavellianism (e.g., manipulation, planfulness, antagonism). While other individual traits (e.g., authoritarianism, sadism, etc.) and models (e.g., Light Triad) do exist, the FFM, HEXACO, and Dark Triad tend to be the most common. 


\section{Why Does Personality Matter?}

At least part of the reason for the enduring legacy of the study of personality is its ability to explain important behavioral outcomes. Individual differences in traits from the FFM, for example, have been associated with outcomes related to health and illness (e.g., Friedman, 2001), educational achievement (e.g., Poropat, 2009), relationship satisfaction (e.g., Malouff et al., 2010), and overall life expectancy (e.g., Hill et al., 2011). More recently, personality has also been identified as an important consideration when studying political behavior (Mondak and Halperin, 2008; Mondak, 2010; Mondak et al., 2010; Gerber et al., 2011a, 2011b, 2013). Rather than reinventing personality structures, these scholars have relied on the existing trait models of personality and applied them to a variety of political outcomes and attitudes including political participation (Vecchione and Caprara, 2009; Mondak, 2010), political interest (Gerber et al., 2011a), vote choice (Barbaranelli et al., 2007; Schoen and Schumann, 2007), political ideology (Chirumbolo and Leone, 2010), political ambition (Blais et al., 2019), and trust (Mondak, 2010). As Dinesen et al. (2016) explain, "individuals think and behave differently politically depending on their personal predispositions, specifically their personality" (p. 56). Likewise, Blais and St-Vincent (2011) write, “if one's personality influences how often one smiles, what kind of music one likes and how one dresses then why should it not have some impact on whether one finds politics interesting or boring and on whether one believes that it is a civic duty to vote" (p. 406)?

While it's clear that personality has much to offer in understanding different political outcomes, research in this area is still in its infancy. We examined three prominent political science journals that publish on the subject of political behavior (Political Behavior; Electoral Studies; and Political Psychology) and three prominent personality psychology journals (Journal of Personality and Social Psychology; Journal of Personality; Personality and Individual Differences) to get a sense of the prevalence of articles dealing with personality as it relates to political outcomes. Through a keyword search and an analysis of titles and abstracts, we documented the prevalence of personality and politics research for the last 21 years (2000-2020). Though only a crude measure, our data provide us with a glimpse into the prominence (or lack thereof) of personality in the study of political outcomes. Outside of some early focus on authoritarianism and social dominance orientation, explorations of personality in political science journals have remained rather niche. Since 2010 , for instance, the pooled data reveal that only about $3 \%$ of articles across the three journals addressed questions relating to personality and politics. More importantly, there has been little change over the period examined. At the same time, articles dealing with personality and political outcomes in prominent personality journals have increased only slightly over the past 21 years. Despite this increase, on average, fewer than $2 \%$ of articles deal with this topic.

\section{Summary of the Research Topic}

A key purpose of this research topic is to highlight the diverse set of questions and approaches that are currently being used in the personality and politics literature. Using a number of different methodologies (surveys, experiments, etc.) our contributors draw on established taxonomies (FFM, HEXACO, Dark Triad, Light Triad), individual traits (authoritarianism, empathy, and openness), and different emotional expressions (e.g., collective nostalgia) to answer a variety of questions relating to tolerance and acceptance of racist speech, attitudes towards welfare recipients, public health compliance, voting for challengers or incumbents, likeability of different candidates, political engagement, and ideology. In this way, this research topic considers myriad of ways that personality can be used to answer important interdisciplinary questions and highlights the importance of personality beyond just the "Big 5."

Several papers in this issue examine the role of personality in shaping attitudes towards political parties and their candidates. Nai et al., for example, employ an experimental study in order to better understand the relationship between perceived personality traits and candidate evaluations. By manipulating the personality profile of a candidate in a randomly assigned vignette, the authors are able to disentangle these ratings from the effects of partisanship, and make a number of important contributions. Among other findings, the authors reveal that the general public tends to rate candidates with dark triad traits lower in likability, but that this is reversed for voters who themselves score higher on these darker traits. Bittner, by contrast, engaging with the personalization of politics literature, considers the extent to which the subjective evaluations of the personality traits of party leaders helps us understand the political behavior of electors-specifically their vote choice. Using longitudinal data that spans five countries and a number of decades, Bittner finds that leader evaluations and leader traits matter for vote choice, but not necessarily more than they did in the past. While leaders (and their traits) certainly matter, it is not clear that personalization (as a process) is indeed occurring. Continuing with the role of personality in developing political preferences, Ramey et al., ask why some electors tend to prefer lesser-known, and therefore riskier candidates, while others favor well-established incumbents. Using the FFM trait of openness, as well as the concept of psychological entropy, the authors reveal that electors higher in openness are more willing to vote for uncertain challengers, but that this is limited to independent respondents who are unable to rely on partisan cues.

The next set of papers considers whether personality can help us understand different attitudes and support for specific policies. Blanchet and Landry, for instance, use the sudden onset of the COVID-19 pandemic as an opportunity to study the relationship between authoritarian dispositions and attitudes towards welfare recipients in Canada. While their results indicate that authoritarianism is indeed associated with more negative views of welfare recipients, their longitudinal data also reveal that the pandemic did not seem to exacerbate 
this relationship. Harell et al., by contrast, use the trait of empathy to better understand political tolerance and the acceptance of racist speech. Drawing on observational and experimental data from Canada and the United States, the authors provide compelling evidence regarding the importance of empathy in the formation of political attitudes. In particular, the authors demonstrate that individuals with higher levels of empathy express less tolerance towards groups engaged in exclusionary and potentially harmful speech. Rounding out the question of personality and policy attitudes, Stefaniak et al., contribution helps contextualize policy differences on the left and right in the context of collective nostalgia. The authors demonstrate that, while both liberals and conservatives long for an idealized view of society, conservatives focus on homogeneity while liberals focus on openness. These differing forms of nostalgia, in turn, translate into protection of in-groups and welcoming of out-groups, respectively.

The final papers explore the relationship between personality and political action. Petersen and Palmer explore the extent to which both the Dark (Machiavellianism, psychopathy, and narcissism) and Light (faith in humanity, Kantianism, and humanism) triads are related to a variety of political behaviors including participation and nascent political ambition. The addition of the Light Triad is an important contribution as the political science literature has yet to meaningfully engage with this particular construct. Overall, the authors find that the dark traits hold considerably more explanatory power compared to those of faith in humanity,

\section{REFERENCES}

Ashton, M. C., and Lee, K. (2007). Empirical, Theoretical, and Practical Advantages of the HEXACO Model of Personality Structure. Pers Soc. Psychol. Rev. 11 (2), 150-166. doi:10.1177/1088868306294907

Barbaranelli, C., Caprara, G. V., Vecchione, M., and Fraley, C. R. (2007). Voters' Personality Traits in Presidential Elections. Personal. Individual Differences. 42, 1199-1208. doi:10.1016/j.paid.2006.09.029

Blais, A., and St-Vincent, S. L. (2011). Personality Traits, Political Attitudes and the Propensity to Vote. Eur. J. Polit. Res. 50 (3), 395-417. doi:10.1111/j.14756765.2010.01935.x

Blais, J., Pruysers, S., and Chen, P. G. (2019). Why Do They Run? the Psychological Underpinnings of Political Ambition. Can. J. Pol. Sci. 52 (4), 761-779. doi:10.1017/S0008423918001075

Campbell, A., Converse, P., Miller, W., and Stokes, D. (1960). The American Voter. Chicago: University of Chicago Press.

Chirumbolo, A., and Leone, L. (2010). Personality and Politics: The Role of the HEXACO Model of Personality in Predicting Ideology and Voting. Personal. Individual Differences. 49, 43-48. doi:10.1016/j.paid.2010.03.004

Converse, P. (1972). "Change in the American Electorate," in The Human Meaning of Social Change. Editors A. Campbell and P. Converse (New York: Russell Sage).

Dinesen, P. T., Klemmensen, R., and Nørgaard, A. S. (2016). Attitudes Toward Immigration: The Role of Personal Predispositions. Polit. Psychol. 37 (1), 55-72. doi:10.1111/pops.12220

Feist, J., and Feist, G. J. (2009). Theories of Personality. 7th ed. New York: McGrawHill.

Friedman, H. S. (2001). Long-Term Relations of Personality and Health: Dynamisms, Mechanisms, Tropisms. J. Personal. 68 (6), 1089-1107. doi:10.1111/1467-6494.00127
Kantianism, and humanism. Finally, Blais et al., draw upon survey data with an embedded experiment to study the relationship between personality (both general and dark traits) and public health compliance. In general, the authors find that prosocial traits (honesty-humility, conscientiousness, and openness) are related to greater public health compliance whereas antisocial traits (Machiavellianism, psychopathy, and narcissism) are related to greater defiance. On the experimental side, the authors find that public health messaging that focusses on the severity of the pandemic can have unintended consequences as some individuals, such as those higher in emotionality, respond with greater compliance, whereas others, such as those higher in antagonism, respond with less compliance.

As we end this brief introduction a word of thanks is warranted. The contributors to this collection produced high quality cutting-edge interdisciplinary research during a global pandemic. We are remarkably grateful for their participation, as well as that of each of the reviewers who provided valuable feedback. Our hope is that the papers in this issue continue to push the study of personality and politics into the mainstream, and that the work published here generates a host of new questions to be addressed.

\section{AUTHOR CONTRIBUTIONS}

All authors listed have made a substantial, direct, and intellectual contribution to the work and approved it for publication.

Gerber, A. S., Huber, G. A., Doherty, D., and Dowling, C. M. (2011a). Personality Traits and the Consumption of Political Information. Am. Polit. Res. 39, 32-84. doi:10.1177/1532673X10381466

Gerber, A. S., Huber, G. A., Doherty, D., and Dowling, C. M. (2011b). The Big Five Personality Traits in the Political arena. Annu. Rev. Polit. Sci. 14, 265-287. doi:10.1146/annurev-polisci-051010-111659

Gerber, A. S., Huber, G. A., Doherty, D., Dowling, C. M., and Panagopoulos, C. (2013). Big Five Personality Traits and Responses to Persuasive Appeals: Results from Voter Turnout Experiments. Polit. Behav. 35 (4), 687-728. doi:10.1007/ s11109-012-9216-y

Hill, P. L., Turiano, N. A., Hurd, M. D., Mroczek, D. K., and Roberts, B. W. (2011). Conscientiousness and Longevity: An Examination of Possible Mediators. Health Psychol. 30, 536-541. doi:10.1037/a0023859

Larsen, R. J., Buss, D. M., King, D. B., and Ensley, C. E. (2018). Personality Psychology: Domains of Knowledge about Human Nature. Toronto: McGrawHill.

Malouff, J. M., Thorsteinsson, E. B., Schutte, N. S., Bhullar, N., and Rooke, S. E. (2010). The Five-Factor Model of Personality and Relationship Satisfaction of Intimate Partners: A Meta-Analysis. J. Res. Personal. 44 (1), 124-127. doi:10.1111/1467-6494.00127

Marsh, A., and Kaase, M. (1979). "Background of Political Action," in Political Action: Mass Participation in Five Western Democracies. Editors S. H. Barnes and M. Kaase (Beverly Hills: Sage Publications).

McCrae, R. R., and Costa, P. T. (1987). Validation of the Five-Factor Model of Personality Across Instruments and Observers. J. Personal. Soc. Psychol. 52 (1), 81-90. doi:10.1037/0022-3514.52.1.81

Mondak, J. J., and Halperin, K. D. (2008). A Framework for the Study of Personality and Political Behaviour. Br. J. Polit. Sci. 38, 335-362. doi:10.1017/ s0007123408000173

Mondak, J. J., Hibbing, M. V., Canache, D., Seligson, M. A., and Anderson, M. R. (2010). Personality and Civic Engagement: An Integrative Framework for the 
Study of Trait Effects on Political Behavior. Am. Polit. Sci. Rev. 104, 85-110. doi:10.1017/S0003055409990359

Mondak, J. (2010). Personality and the Foundations of Political Behavior. New York: Cambridge University Press. doi:10.1017/ cbo9780511761515

Paulhus, D. L., and Williams, K. M. (2002). The Dark Triad of Personality: Narcissism, Machiavellianism, and Psychopathy. J. Res. Personal. 36 (6), 556-563. doi:10.1016/S0092-6566(02)00505-6

Poropat, A. E. (2009). A Meta-Analysis of the Five-Factor Model of Personality and Academic Performance. Psychol. Bull. 135 (2), 322-338. doi:10.1037/ a0014996

Schoen, H., and Schumann, S. (2007). Personality Traits, Partisan Attitudes, and Voting Behavior. Evidence from Germany. Polit. Psychol. 28 (4), 471-498. doi:10.1111/j.1467-9221.2007.00582.x
Vecchione, M., and Caprara, G. V. (2009). Personality Determinants of Political Participation: The Contribution of Traits and Self-Efficacy Beliefs. Personal. Individual Differences. 46, 487-492. doi:10.1016/j.paid.2008.11.021

Conflict of Interest: The authors declare that the research was conducted in the absence of any commercial or financial relationships that could be construed as a potential conflict of interest.

Copyright $\odot 2021$ Blais, Chen and Pruysers. This is an open-access article distributed under the terms of the Creative Commons Attribution License (CC BY). The use, distribution or reproduction in other forums is permitted, provided the original author(s) and the copyright owner(s) are credited and that the original publication in this journal is cited, in accordance with accepted academic practice. No use, distribution or reproduction is permitted which does not comply with these terms. 